\title{
Impact of Socioeconomic Factors on Outcome of Total Knee Arthroplasty
}

\author{
Robert L. Barrack MD, Erin L. Ruh MS, Jiajing Chen MPH, Adolph V. Lombardi Jr MD, \\ Keith R. Berend MD, Javad Parvizi MD, FRCS, Craig J. Della Valle MD, \\ William G. Hamilton MD, Ryan M. Nunley MD
}

Published online: 30 April 2013

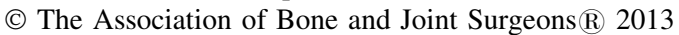

\begin{abstract}
Background Few data exist regarding the impact of socioeconomic factors on results of current TKA in young patients. Predictors of TKA outcomes have focused primarily on surgical technique, implant details, and individual patient clinical factors. The relative importance of these factors compared to patient socioeconomic status is not known.

Questions/purposes We determined whether (1) socioeconomic factors, (2) demographic factors, or (3) implant factors were associated with satisfaction and functional outcomes after TKA in young patients.
\end{abstract}

The institution of one or more of the authors has received funding from Biomet Inc (Warsaw, IN, USA) (RLB, AVL, KRB, WGH, RMN), EOS Imaging Inc (Cambridge, MA, USA) (RLB, RMN), Medical Compression Systems, Inc (West Hills, CA, USA) (RLB, RMN), NIH (Bethesda, MD, USA) (RLB, JP), Smith \& Nephew, Inc (Memphis, TN, USA) (RLB, JP, CDV, RMN), Stryker Orthopaedics (Mahwah, NJ, USA) (RLB, AVL, JP, CDV, RMN), Wright Medical Technology, Inc (Arlington, TN, USA) (RLB, RMN), DePuy, a Johnson and Johnson company (Warsaw, IN, USA) (JP, WGH), 3 M (St Paul, MN, USA) (JP), Baxter Healthcare Corp (Deerfield, IL, USA) (JP), Musculoskeletal Transplant Foundation (Edison, NJ, USA) (JP), Zimmer Inc (Warsaw, IN, USA) (JP), and Inova Health Care Services (Falls Church, VA, USA) (WGH). The institutions of the authors have received funding from Stryker Orthopaedics in support of this study.

One of the authors certifies that he (RLB) has or may receive payments or benefits, during the study period, an amount of more than USD 1,000,001 from Smith \& Nephew, Inc, and an amount of more than USD 1,000,001 from Stryker Orthopaedics.

One of the authors certifies that he (AVL) has or may receive payments or benefits, during the study period, an amount of more than USD 1,000,001 from Biomet Inc, and an amount of USD 10,000 to 100,000 from Innomed, Inc (Savannah, GA, USA).

One of the authors certifies that he (KRB) has or may receive payments or benefits, during the study period, an amount of more than USD 1,000,001 from Biomet Inc.
Methods We surveyed 661 patients (average age, 54 years; range, $18-60$ years; $61 \%$ female) 1 to 4 years after undergoing modern primary TKA for noninflammatory arthritis at five orthopaedic centers. Data were collected by an independent third party with expertise in collecting healthcare data for state and federal agencies. We examined specific questions regarding satisfaction, pain, and function after TKA and socioeconomic (household income, education, employment) and demographic (sex, minority status) factors. Multivariable analysis was conducted to examine the relative importance of these factors for each outcome of interest.

One of the authors certifies that he (JP) has or may receive payments or benefits, during the study period, an amount of USD 10,000 to 100,000 from Smith \& Nephew, Inc, an amount of USD 10,000 to 100,000 from $3 \mathrm{M}$, an amount of USD 10,000 to 100,000 from Cadence Pharmaceuticals, Inc (San Diego, CA, USA), an amount of USD 10,000 to 100,000 from CeramTec (Laurens, SC, USA), an amount of USD 10,000 to 100,000 from Pfizer (New York, NY, USA), an amount of USD 10,000 to 100,000 from Salient Surgical (Minneapolis, MN, USA), an amount of USD 10,000 to 100,000 from TissueGene (Rockville, MD, USA), and an amount of USD 10,000 to 100,000 from Zimmer Inc.

One of the authors certifies that he (CDV) has or may receive payments or benefits, during the study period, an amount of USD 10,000 to 100,000 from Biomet Inc, an amount of USD 10,000 to 100,000 from Smith \& Nephew, Inc, an amount of less than USD 10,000 from ConvaTec (Skillman, NJ, USA), and an amount of less than USD 10,000 from CD Diagnostics (Wynnewood, PA, USA). One of the authors certifies that he (WGH) has or may receive payments or benefits, during the study period, an amount of USD 100,001 to $1,000,000$ from DePuy, a Johnson and Johnson company, and an amount of USD 10,000 to 100,000 from Medtronic. One of the authors certifies that he (RMN) has or may receive payments or benefits, during the study period, an amount of less than USD 10,000 from Smith \& Nephew, Inc, an amount of less than USD 10,000 from Wright Medical Technology, Inc, an amount of less than USD 10,000 from Medtronic (Minneapolis, MN, USA), an amount of 
Results Patients reporting incomes of less than USD 25,000 were less likely to be satisfied with TKA outcomes and more likely to have functional limitations after TKA than patients with higher incomes; no other socioeconomic factors were associated with satisfaction. Women were less likely to be satisfied and more likely to have functional limitations than men, and minority patients were more likely to have functional limitations than nonminority patients. Implants were not associated with outcomes after surgery.

Conclusions Socioeconomic factors, in particular low income, are more strongly associated with satisfaction and functional outcomes in young patients after TKA than demographic or implant factors. Future studies should be directed to determining the causes of this association, and studies of clinical results after TKA should consider stratifying patients by socioeconomic status.

Level of Evidence Level III, therapeutic study. See Instructions for Authors for a complete description of levels of evidence.

\section{Introduction}

TKA is among the highest-volume, most rapidly growing procedures in medicine, with more than three million procedures annually projected in the United States by the year 2025 [34]. While originally considered a procedure for older, less active patients, in the past decade, younger and presumably more active patients have been the fastest growing segment of the TKA population [35]. TKA in young patients has been associated with higher rates of revision [63] and residual symptoms and dissatisfaction

less than USD 10,000 from CardioMEMS (Atlanta, GA, USA), and an amount of less than USD 10,000 from Integra LifeSciences (Plainsboro, NJ, USA).

Each author certifies that his or her institution approved the human protocol for this investigation, that all investigations were conducted in conformity with ethical principles of research, and that informed consent for participation in the study was obtained.

All ICMJE Conflict of Interest Forms for authors and Clinical Orthopaedics and Related Research editors and board members are on file with the publication and can be viewed on request.

This work was performed at Washington University School of Medicine (St Louis, MO, USA), Joint Implant Surgeons, Inc (New Albany, OH, USA), Rothman Institute of Orthopedics at Thomas Jefferson University (Philadelphia, PA, USA), Midwest Orthopaedics at Rush (Chicago, IL, USA), and Anderson Orthopaedic Clinic (Arlington, VA, USA)

R. L. Barrack (凹), E. L. Ruh, R. M. Nunley

Department of Orthopaedic Surgery, Washington University

School of Medicine, One Barnes-Jewish Hospital Plaza,

11300 West Pavilion, St Louis, MO 63110, USA

e-mail: barrackr@wustl.edu; pouchera@wustl.edu
[50]. Surgical techniques and component designs have evolved in recent years that have focused on improving function and outcome after TKA. Mobile bearing TKA [16], sex-specific TKA [6], high-flexion TKA [40, 55], and refinements in the design of cruciate-retaining $(\mathrm{CR})$ and posterior-stabilized (PS) TKA [4, 14, 33, 64] have all been introduced in recent years. In addition, improvements in perioperative management, including more limited incisions [62] and multimodal pain management [23, 44], have been instituted to speed the recovery process and potentially improve the ultimate patient outcome and satisfaction with TKA.

Most previous reports of limitations of TKA, especially in younger, more active patients, preceded these changes in surgical technique and component design. Substantial gaps remain regarding the clinical outcome in young patients after TKA, including their degree of residual symptoms and functional limitations after TKA with modern designs and current perioperative treatment protocols. Prior studies commonly had substantial limitations, including limited sample size with inadequate statistical power, study groups that rarely focused on the patient population younger than 60 years who are typically in the workforce and frequently participating in more demanding activities in recreation and at work, and possibly most important, the specter of observer bias, with data collection commonly performed by the research staff of the surgeon, often at the physician's office. Surgeons and patients often view the results of joint arthroplasty differently, especially when suboptimal results are achieved [38].

To address the gap in knowledge of results of modern TKA in young patients, a new paradigm was developed to evaluate a large cohort of young patients who had recently

J. Chen

Division of Biostatistics, Washington University School of Medicine, St Louis, MO, USA

A. V. Lombardi Jr, K. R. Berend

Joint Implant Surgeons, Inc, New Albany, OH, USA

J. Parvizi

Rothman Institute of Orthopedics, Thomas Jefferson University, Philadelphia, PA, USA

C. J. Della Valle

Midwest Orthopaedics at Rush, Chicago, IL, USA

W. G. Hamilton

Anderson Orthopaedic Clinic, Arlington, VA, USA 
undergone TKA with modern implants and current perioperative management. Data collection was completed in a blinded manner by an independent survey center with the purpose of determining the current outcomes of TKA in young patients.

A topic of great interest in recent years is access to care and clinical results among patients with different demographic characteristics after TKA. One recent study reported socioeconomic factors substantially impacted the patients' perceived clinical outcome after cementless THA [10], but few data exist on this topic after modern TKA.

We therefore determined whether (1) socioeconomic factors (such as household income, education level, or employment status); (2) demographic factors (such as sex or minority status); or (3) implant factors (CR, PS, mobile bearing, sex-specific, and high-flexion) were associated with satisfaction and functional outcomes after TKA in young patients.

\section{Patients and Methods}

A study group of five total joint centers from five different US geographic areas (Arlington, VA; Chicago, IL; New Albany, OH; Philadelphia, PA; St Louis, MO) was selected to participate in this multicenter data collection study. The centers utilized different types of implants including the current primary TKA implant designs of the leading five American manufacturers. Component selection was based on the criteria for the surgeon at each site for patients 60 years or younger. All centers utilized modern multimodal pain management perioperative protocols, regional anesthesia, and rapid mobilization. Institutional review board (IRB) approval was obtained for Washington University to serve as the coordinating center. Each participating center obtained approval from its IRB of oversight. All five centers had registries in place that allowed them to produce a list of consecutive patients who met inclusion criteria including age, date of surgery, and complete contact information. Patients were systematically excluded for complications that would compromise results and medical comorbidities that would limit their activity level.

There were 1139 potential participants who met met the inclusion criteria and were sent to the survey center for contact. Of those, there were 112 screen failures, 54 refusals at the household level, and 69 participant refusals. An additional 114 participants were never available, 109 were not found due to bad address/telephone number, eight were deceased, seven were contacted but did not complete the interview, and five had a language barrier preventing them from completing the survey. This left 661 completed interviews for final analysis. The American Association for
Table 1. Descriptive statistics of socioeconomic variables (total $\mathrm{n}=661$ )

\begin{tabular}{lc}
\hline Socioeconomic variable & Number of patients \\
\hline Sex $(\mathrm{n}=661)$ & \\
Male & $256(39 \%)$ \\
Female & $405(61 \%)$ \\
Minority $(\mathrm{n}=658)$ & \\
Hispanic or black & $85(13 \%)$ \\
Other & $573(87 \%)$ \\
Education (n =658) & $18(3 \%)$ \\
Less than high school graduate & $640(97 \%)$ \\
High school graduate and above & \\
Income (n $=604)$ & $68(11 \%)$ \\
$<$ USD 25,000 & $536(89 \%)$ \\
$\geq$ USD 25,000 & \\
Employment 3 months before surgery $(\mathrm{n}=660)$ \\
Yes & $494(75 \%)$ \\
No & $166(25 \%)$ \\
Implant type (n = 661) & \\
Cruciate-retaining & $346(52 \%)$ \\
Posterior-stabilized & $181(27 \%)$ \\
Rotating-platform & $61(9 \%)$ \\
High-flexion & $42(6 \%)$ \\
Sex-specific & $31(5 \%)$ \\
\hline
\end{tabular}

Public Opinion Research response rate calculator was used for the calculation of the overall response rate to compute the percentage of all eligible or potentially eligible patients that resulted in a completed interview.

$$
\begin{aligned}
& \frac{\text { number of completed interviews }}{\text { total sample }- \text { known ineligible sample }}=\frac{661}{(1139-112)} \\
& =64 \% \text { response rate }
\end{aligned}
$$

The final study group had an average age of 54 years at the time of surgery with $61 \%$ female, and they were contacted at a mean of 2.6 years (range, 1-4.7 years) postoperatively. Descriptive statistics of socioeconomic variables (Table 1) and outcomes of interest (Table 2) are presented.

The University of Wisconsin Survey Center (UWSC) at the University of Wisconsin-Madison (Madison, WI, USA) was selected for their expertise in collecting health data for state and federal agencies $[12,51]$ and having no affiliation with any of the participating centers. UWSC designed an instrument that would collect specific, unique data we sought to collect on the level of satisfaction, function, residual symptoms, ability to return to previous employment (with or without limitations), and the ability to return to the most preferred preoperative activity 1 to 4 years after TKA. The survey was administered utilizing 
Table 2. Descriptive statistics of outcomes of interest (total $\mathrm{n}=661)$

\begin{tabular}{|c|c|}
\hline Outcome of interest & Number of patients \\
\hline \multicolumn{2}{|c|}{ Satisfaction with overall knee function $(\mathrm{n}=658)$} \\
\hline Satisfied & $594(90 \%)$ \\
\hline Dissatisfied & $64(10 \%)$ \\
\hline \multicolumn{2}{|c|}{ Satisfaction with ability to perform daily activities $(n=660)$} \\
\hline Satisfied & $585(89 \%)$ \\
\hline Dissatisfied & $75(11 \%)$ \\
\hline \multicolumn{2}{|c|}{ Satisfaction with the degree of pain relief $(n=657)$} \\
\hline Satisfied & $598(91 \%)$ \\
\hline Dissatisfied & $59(9 \%)$ \\
\hline \multicolumn{2}{|c|}{ Problems getting in and out of a car $(\mathrm{n}=659)$} \\
\hline Yes & $251(38 \%)$ \\
\hline No & $408(62 \%)$ \\
\hline \multicolumn{2}{|c|}{ Problems getting in and out of a chair $(n=661)$} \\
\hline Yes & $200(30 \%)$ \\
\hline No & $461(70 \%)$ \\
\hline \multicolumn{2}{|c|}{ Difficulty going up and down stairs $(n=651)$} \\
\hline Difficult & $167(26 \%)$ \\
\hline Not difficult & $484(74 \%)$ \\
\hline \multicolumn{2}{|c|}{ Experienced pain in the last 30 days $(\mathrm{n}=661)$} \\
\hline Yes & $215(33 \%)$ \\
\hline No & $446(67 \%)$ \\
\hline \multicolumn{2}{|c|}{ Operated knee feels normal $(\mathrm{n}=658)$} \\
\hline Yes & $433(66 \%)$ \\
\hline No & $225(34 \%)$ \\
\hline \multicolumn{2}{|c|}{ Limp while walking $(\mathrm{n}=659)$} \\
\hline Yes & $202(31 \%)$ \\
\hline No & $457(69 \%)$ \\
\hline \multicolumn{2}{|c|}{ Participated in preferred activity in the last 30 days $(n=469)$} \\
\hline Yes & $234(50 \%)$ \\
\hline No & $235(50 \%)$ \\
\hline
\end{tabular}

computer-assisted telephone interviewing as per previously described methodology [47]. A formal pretest was conducted to review the flow of questions and to ensure the efficiency and practicality of the interview process to obtain the required data. Only the contact information and date and side of surgery were provided to UWSC. The implant type was removed by the coordinating center before transferring the contact information to UWSC to assure an anonymous, blinded administration of the survey was performed. The coordinating center maintained a comprehensive list of implant details to decode by implant type after interviews were complete and before data analysis. Each center mailed advance notification letters to its patients approximately 1 week before its respective batch entered the field. Interviewers read a telephone script to obtain verbal consent before administering the survey. A screening section ensured participants met inclusion criteria. Participants who did not fail screening proceeded to answer a series of questions regarding satisfaction and return to activity, pain relief, and employment (Appendix 1).

The satisfaction section was constructed from a review of recent investigations detailing patient satisfaction and function after TKA $[8,46]$. Questions selected were based on previous studies determining factors most important to patients and/or most highly correlated with patient satisfaction as reported by Bourne et al. [8] and Noble et al. [46]. Questions regarding symptoms or function had five choices for responses as described by Likert [39]. For purposes of analysis, the responses were grouped into two broad categories of either "never/rarely" or "sometimes/ often/frequent," similar to the methodology described by Bourne et al. [8]. Patients were asked whether their operated knee felt normal to them, as described by Noble et al. [46]. The Patient-Specific Functional Scale [15, 25, 60] was incorporated to determine whether there were one or more activities critical to the patient in their recreation that they had to limit participation in before surgery because of their knee. We then examined the percentage of patients who returned to this critical activity after surgery. Demographic data collected included sex, minority status (black or Hispanic), household income (in increments of USD 25,000 up to $>$ USD 100,000), education level, and employment status (worked for pay within the 3 months before TKA) (Appendix 2).

Descriptive statistics were performed to examine the frequency of responses for each variable. Pearson's chisquare or Fisher's exact test was used to assess the association between categorical socioeconomic variables (eg, male versus female, minority versus nonminority, implant type) and the outcomes of interest. We then conducted forward stepwise multiple logistic regression to reexamine the association when adjusting for socioeconomic factors and to calculate adjusted odds ratios and 95\% CIs associated with selected outcome measures. One of the authors (JC) performed all analyses using SAS ${ }^{\circledR} 9.2$ (SAS Institute Inc, Cary, NC, USA) with an alpha level at 0.05 considered significant.

\section{Results}

Patients from households reporting an income of less than USD 25,000 were less likely to be satisfied with the results of TKA and were more likely to have functional limitations after TKA than patients from higher-income households (Table 3); no other socioeconomic factors were associated with satisfaction. Household income emerged as a far more important predictor of lower satisfaction and functional limitations than any other variable in the multivariable 
analysis (Table 4). Results for low-income households remained consistent with the univariate analysis, with those patients having worse results on nine of the 10 questions in the survey than patients from higher-income households. Patients with less than high school education had worse results on four of 10 questions than patients who were high school graduates and above (Table 3), but none of these results showed significance after adjusting for socioeconomic factors. Patients not employed in the 3 months before surgery had more functional limitations, in particular problems getting in and out of a chair, than patients who were employed before surgery (Table 4).

Women were less likely to be satisfied, were more likely to have difficulty with stairs, and reported experiencing more pain in the last 30 days than men (Table 4). Women were associated with one positive result, having participated in their preferred activity more often in the last 30 days than men, which might imply their most favored activity was not as demanding, although other explanations are possible. After adjusting for socioeconomic factors, minority patients were more likely to have problems getting in and out of a car and chair and were more likely to report a limp than nonminority patients.

The TKA implant utilized was not associated with satisfaction or functional outcomes after surgery. There were no differences observed in any domain based on implant type (classified according to femoral implant model: CR, PS, mobile bearing, sex-specific, and high-flexion), and this variable was therefore excluded from the multivariable analysis.

\section{Discussion}

Few data exist regarding the impact of socioeconomic factors on the results of current TKA in young patients. Predictors of TKA outcomes have focused primarily on surgical technique, implant details, and individual patient clinical factors. The relative importance of these factors compared to patient socioeconomic status is not known. We therefore defined the association, if any, between demographic and socioeconomic factors and clinical outcomes after TKA and compared the strength of that association with that of implant type on patient satisfaction after TKA in young patients.

This study had a number of limitations. First, we studied an association that does not prove causation, although it does show that the impact of socioeconomic factors on the perceived satisfaction after TKA warrants further investigation. Second, most of the factors under consideration are patient factors, ie, sex, economic status, race, etc, but there is a complex interplay between these factors and possible prejudices of caregivers, which may affect results as much or more than the patient factors themselves. Third, different centers used different implants but also may have had different populations, indications, techniques, and surgeon outcomes, and this may have confounded the results with respect to implant effect. Each center was selected to represent the various major types of components in current use and each center predominantly used specific component types; for this reason, we chose to focus our analysis on implant factors. Fourth, this was a retrospective study of patients who were at least 1 year postoperative, which introduced the potential for recall bias. We limited the date range for inclusion in an attempt to minimize this concern, which resulted in a mean followup of only 2.6 years. Furthermore, as a retrospective study, there are no baseline data to indicate whether or not the level of pain and function of the low-income, female, or minority patients was similar to that of the other patients, and we must acknowledge that unknown differences in these factors may have affected the results and conclusions of the study.

Additionally, a number of patient factors other than socioeconomic status have been reported as being associated with an inferior outcome after TKA, including a low preoperative WOMAC or SF-36 score (especially the mental component score) [1, 21, 36], high BMI [21, 54, 56], medical comorbidities [20, 56], Workers Compensation status [45], preoperative depression [9], pain catastrophizing [53], and a pessimistic explanatory style [57]. None of these factors was assessed in this study. This is a weakness of the study, but the study design evaluated numerous domains of patient characteristics and various assessments of clinical outcome, which taxed the limit of the time to reasonably obtain this volume of information in a single voluntary interview. The telephone questionnaire was a novel development and was not formally validated. However, the selected questions were based on previous studies assessing patient satisfaction and function after TKA $[8,46]$ and were scored and reported according to previously described methodology [8, 39]. UWSC staff helped design a questionnaire using the most valid rating scales and reliable research methods. The questions were tested on a sample population, and the telephone algorithm was developed by professionals in healthcare data collection [12, 51]. Although we did not conduct a formal analysis on the validity of questionnaire followup, we previously conducted a similar study with patients having undergone hip arthroplasty in which we achieved a similar response rate $(65 \%)$ [3]. The percentage of followup is another study weakness, but more than $64 \%$ of patients meeting inclusion criteria did achieve successful interview completion, which is a high percentage for surveys of this type.

Socioeconomic parameters, specifically low household income, had a substantial impact on satisfaction and 


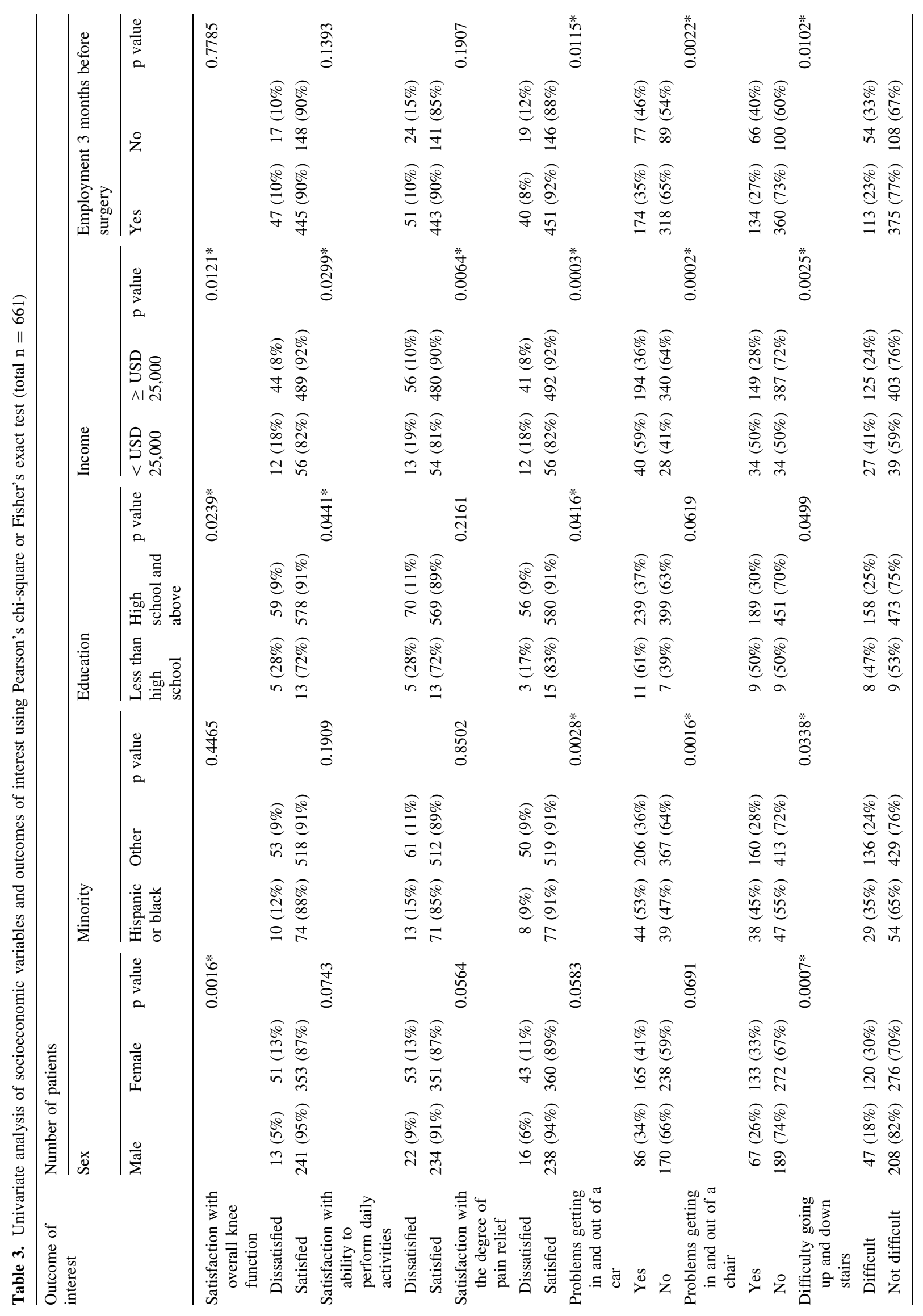




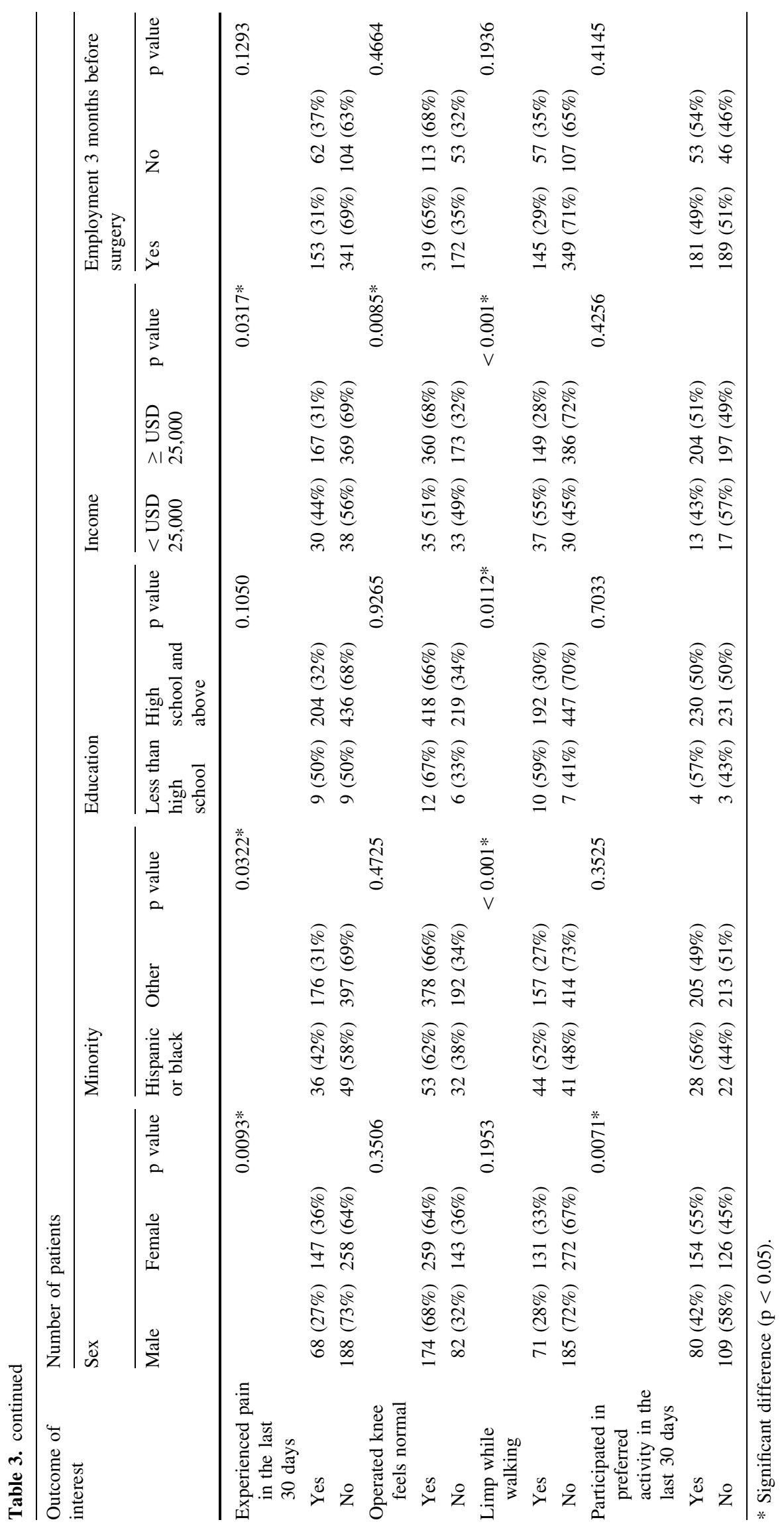


Table 4. Adjusted odds ratio of socioeconomic factors significantly associated with outcomes of interest using forward stepwise multiple logistic regression (total $\mathrm{n}=661$ )

\begin{tabular}{|c|c|c|c|c|c|}
\hline \multirow[t]{2}{*}{ Outcome measure } & \multirow[t]{2}{*}{$\mathrm{R}^{2}$ value } & \multicolumn{4}{|c|}{ Odds ratio $(95 \% \mathrm{CI})^{*}$} \\
\hline & & Female & Hispanic or black & Income $<$ USD 25,000 & $\begin{array}{l}\text { Employed } \\
3 \text { months } \\
\text { before surgery }\end{array}$ \\
\hline $\begin{array}{l}\text { Dissatisfied with overall } \\
\text { knee function }\end{array}$ & 0.068 & $\begin{array}{l}3.13(1.54,6.35) \\
(\mathrm{p}=0.0016)\end{array}$ & & $\begin{array}{l}2.29(1.13,4.64) \\
(p=0.0211)\end{array}$ & \\
\hline $\begin{array}{l}\text { Dissatisfied with ability to } \\
\text { perform daily activities }\end{array}$ & 0.027 & $\begin{array}{l}1.76(1.01,3.07) \\
(\mathrm{p}=0.0472)\end{array}$ & & $\begin{array}{l}2.01(1.03,3.93) \\
(\mathrm{p}=0.0407)\end{array}$ & \\
\hline $\begin{array}{l}\text { Dissatisfied with the degree } \\
\text { of pain relief }\end{array}$ & 0.041 & $\begin{array}{l}2.03(1.06,3.90) \\
(\mathrm{p}=0.0330)\end{array}$ & & $\begin{array}{l}2.49(1.23,5.04) \\
(\mathrm{p}=0.0111)\end{array}$ & \\
\hline $\begin{array}{l}\text { Problems getting in and } \\
\text { out of a car }\end{array}$ & 0.037 & & $\begin{array}{l}1.67(1.01,2.78) \\
(p=0.0469)\end{array}$ & $\begin{array}{l}2.12(1.23,3.64) \\
(p=0.0068)\end{array}$ & \\
\hline $\begin{array}{l}\text { Problems getting in and } \\
\text { out of a chair }\end{array}$ & 0.052 & & $\begin{array}{l}1.75(1.05,2.92) \\
(p=0.0316)\end{array}$ & $\begin{array}{l}1.83(1.04,3.22) \\
(p=0.0361)\end{array}$ & $\begin{array}{l}0.63(0.42,0.95) \\
(\mathrm{p}=0.0275)\end{array}$ \\
\hline $\begin{array}{l}\text { Difficulty going up and } \\
\text { down stairs }\end{array}$ & 0.052 & $\begin{array}{l}2.07(1.37,3.10) \\
(\mathrm{p}=0.0005)\end{array}$ & & $\begin{array}{l}2.16(1.26,3.69) \\
(\mathrm{p}=0.0050)\end{array}$ & \\
\hline $\begin{array}{l}\text { Experienced pain in the } \\
\text { last } 30 \text { days }\end{array}$ & 0.027 & $\begin{array}{l}1.65(1.15,2.36) \\
(\mathrm{p}=0.0070)\end{array}$ & & $\begin{array}{l}1.70(1.01,2.85) \\
(\mathrm{p}=0.0440)\end{array}$ & \\
\hline $\begin{array}{l}\text { Operated knee does not } \\
\text { feel normal }\end{array}$ & 0.015 & & & $\begin{array}{l}1.95(1.17,3.25) \\
(\mathrm{p}=0.0010)\end{array}$ & \\
\hline Limp while walking & 0.061 & & $\begin{array}{l}2.04(1.23,3.39) \\
(p=0.0060)\end{array}$ & $\begin{array}{l}2.51(1.45,4.35) \\
(p=0.0010)\end{array}$ & \\
\hline $\begin{array}{l}\text { Did not participate in preferred } \\
\text { activity in the last } 30 \text { days }\end{array}$ & 0.017 & $\begin{array}{l}0.63(0.43,0.93) \\
(\mathrm{p}=0.0203)\end{array}$ & & & \\
\hline
\end{tabular}

* Reference groups in the comparison: male, other ethnicity/race, high school graduate or above, income $\geq$ USD 25,000, not employed 3 months before surgery.

functional outcomes after TKA. Patients in the lowest category for household income did worse in nine of 10 domains than patients from higher-income households, which indicates household income was more important than minority status in predisposing to suboptimal results. These findings are similar to those of a recent randomized trial reported by Butler et al. [10] after cementless THA in which implant type had no impact on any outcome scores while patients from low-income households were associated with inferior clinical results. Freburger et al. [22] reported low-income patients who underwent TKA received less postacute care rehabilitation services, a finding that could potentially contribute to the suboptimal clinical results observed in the low-income cohort in our study, although we did not collect rehabilitation data.

While women reported lower satisfaction than men, the overall rate of dissatisfaction in this study was less than $10 \%$ or approximately $1 / 2$ of that reported from two largescale studies from the National Joint Registry for England and Wales and London, Ontario, Canada, which reported dissatisfaction rates of $18 \%$ and $19 \%$, respectively $[2,8]$. This was despite the fact that our patients were younger (60 years or younger at surgery), which has been reported to be associated with a high rate of dissatisfaction in some studies $[5,50]$. After adjusting for socioeconomic factors, minority patients (Hispanic and black) reported inferior results on three of the functional outcome measures, which points to the importance of multivariable analysis to account for variables that may be interrelated (such as household income and minority status). Lavernia et al. [37] recently reported lower postoperative scores among minority patients; however, household income was not reported, so it is difficult to determine whether it was race or income that was the most important factor contributing to the inferior results. Most previous studies on socioeconomic factors and TKA have focused on complication rates and access to care and services. Two studies have reported higher complication rates among minority patients [26, 48]. Others have reported minorities have less access to TKA $[52,58]$. Lower utilization of TKA by patients with fewer resources has also been reported [24, 27]. Dunlop et al. [17], on the other hand, reported, although there were lower rates of TKA among minority patients, this pattern was not seen in those younger than 65 years, which was the age of our patient population. Our data indicate, in our population of younger, predominantly employed patients $(75 \%)$, household income was far more predictive of outcome than minority status. Epstein et al. [19] reported minority patients were less likely to go to surgeons at high-volume hospitals. This finding was confirmed by Cai et al. [11] 
who reported black patients were more likely to receive care in low-volume hospitals. All of our patients received their TKAs in high-volume total joint centers, which may in part explain the better results reported in our study and the minimal impact of minority status alone on the outcome measures.

No statistically significant differences were observed based on femoral component design on any question. The minimal differences observed based on component design are consistent with previous reports that have been unable to demonstrate a difference in PS versus CR TKA [29, 41], mobile bearing versus fixed bearing TKA [28, 30-32, 49], high-flexion versus standard TKA [18], or sex-specific versus no-sex-specific TKA [7, 42, 59, 61]. The poor results in young patients reported by Price et al. [50] were achieved with implants and surgical techniques from more than 10 years ago and it is certainly possible that the improved level of satisfaction of our patients may be due, in part, to improvements in surgical technique and component design. All of our patients were from high-volume centers with total joint programs utilizing current component designs and surgical techniques including perioperative care, which could contribute to the relatively high rate of overall satisfaction. Despite the high rate of overall satisfaction, there was a substantial incidence of positive responses to specific questions regarding residual symptoms and functional difficulties.

Patient-focused outcomes have been the subject of increasing attention in recent years. Patient satisfaction has recently been recognized as a quality measure by the Centers for Medicare \& Medicaid Services [13] and it is likely in the future TKA reimbursement will be linked to various measures of patient satisfaction. Our study indicates socioeconomic factors, particularly low household income, are associated with lower levels of patient satisfaction and numerous functional limitations after TKA. Despite the apparent association of socioeconomic factors with the outcome of TKA, race and income are rarely, if ever, mentioned in the Materials and Methods sections of published reports of TKA results, which most frequently focus on implant design, which we found to have the least effect on outcomes. Based on our findings, the impact of socioeconomic factors on TKA warrants further study. These parameters should be collected and reported in clinical studies, particularly in registries such as those under development in the United States [43]. If the strong association between socioeconomic category (low income, race, and sex) and inferior clinical results is confirmed by larger-scale studies, further investigation should attempt to understand the origin of the inferior results associated with these groups of patients and mitigate any factors potentially contributing to the inferior results, such as improving postacute care for lower-income patients, which appears to be an issue according to the study by Freburger et al. [22]. Our study only reported an association that does not prove causation, but it does show that the impact of socioeconomic factors on the perceived satisfaction after TKA is a topic worthy of further study. It is certainly possible, based on our results, that socioeconomic factors, particularly household income, may be strongly associated with satisfaction and functional results. Future studies should be directed to determining the causes of this association, and if further studies, do, in fact, confirm this hypothesis, then studies of clinical results after TKA should consider stratifying patients by socioeconomic status. This would be a more accurate reflection of the quality and success of the surgical episode of care, rather than the patient's status, and would avoid the unintended consequence of penalizing surgeons or centers that treat a disproportionate number of patients in socioeconomic groups that may currently be predisposed to inferior clinical outcomes.

Acknowledgments We thank the UWSC, especially John Stevenson BA and Bob Cradock MS, for all their help completing this project and Angel Poucher AAS for her assistance preparing the manuscript.

\section{Appendix 1}

Telephone Questionnaire: Outcomes of Interest

\section{Satisfaction Section}

1. Since you had the operation on your (left/right) knee, are you satisfied, dissatisfied, or in-between with the overall functioning of your knee?

If "in-between": Do you lean more toward satisfied or dissatisfied?

2. Since you had the operation on your (left/right) knee, are you satisfied with your ability to perform your normal activities of daily living?

3. Since you had the operation on your (left/right) knee, are you satisfied with the degree of pain relief?

4. Do you have problems getting in and out of a car? Never, rarely, sometimes, often, or extremely often

5. Do you have problems getting in and out of a chair? Never, rarely, sometimes, often, or extremely often

6. How difficult is it for you to go up and down stairs because of the operation on your knee?

Not at all difficult, a little difficult, somewhat difficult, quite difficult, very difficult, or extremely difficult

7. In the last 30 days, about how often did you experience any pain in your (left/right) knee? Never, rarely, sometimes, often, or extremely often

8. Does your (left/right) knee that was operated on feel normal to you? 
Activity Section

9. How often do you limp while walking? Never, rarely, sometimes, very often, or extremely often

Patient-Specific Functional Scale - Sports/Hobby Section

10. During the last 30 days, how often did you (do/play/ etc) Activity 1 ?

\section{Appendix 2}

Telephone Questionnaire: Demographic Section

1. Do you consider yourself to be Hispanic or Latino?

2. Which of the following categories best describes your race?

Black or African American, Asian, White, Native Hawaiian or other Pacific Islander, Native American or Alaska Native, or Something Else

3. If "Something Else": How would you describe your race?

4. What is the highest grade or year of school you completed?

Never attended school or attended only kindergarten, Grades 1 through 8 (elementary), Grades 9 through 11 (some high school), Grade 12 or GED (high school graduate), College 1 year to 3 years (some college or technical school), College 4 years or more (college graduate), or Postgraduate 1 year or more

5. How many members of your household, including yourself, are 18 years of age or older?

6. How many children younger than 18 years of age live in your household?

7. What is your annual household income from all sources?

Less than USD 25,000 , USD 25,000 to less than USD 50,000 , USD 50,000 to less than USD 75,000, USD 75,000 to less than USD 100,000 , or USD 100,000 or more

8. In the 3 months before your knee operation, did you work for pay at all?

\section{References}

1. Ayers DC, Franklin PD, Ploutz-Snyder R, Boisvert CB. Total knee replacement outcome and coexisting physical and emotional illness. Clin Orthop Relat Res. 2005;440:157-161.
2. Baker PN, van der Meulen JH, Lewsey J, Gregg PJ; National Joint Registry for England and Wales. The role of pain and function in determining patient satisfaction after total knee replacement. Data from the National Joint Registry for England and Wales. J Bone Joint Surg Br. 2007;89:893-900.

3. Barrack RL, Ruh EL, Berend ME, Della Valle CJ, Engh CA Jr, Parvizi J, Clohisy JC, Nunley RM. Do Young, Active Patients Perceive Advantages After Surface Replacement Compared to Cementless Total Hip Arthroplasty? Clin Orthop Relat Res. 2013 March 19 [Epub ahead of print].

4. Blaha JD. The rationale for a total knee implant that confers anteroposterior stability throughout range of motion. J Arthroplasty. 2004;19:22-26.

5. Bonnin MP, Basiglini L, Archbold HA. What are the factors of residual pain after uncomplicated TKA? Knee Surg Sports Traumatol Arthrosc. 2011;19:1411-1417.

6. Booth RE Jr. Sex and the total knee: gender-sensitive designs. Orthopedics. 2006;29:836-838.

7. Bourne R. A gender-specific prosthesis was similar to a standard prosthesis in women having total knee replacement. $J$ Bone Joint Surg Am. 2011;93:396.

8. Bourne RB, Chesworth BM, Davis AM, Mahomed NN, Charron KD. Patient satisfaction after total knee arthroplasty: who is satisfied and who is not? Clin Orthop Relat Res. 2010;468:57-63.

9. Brander VA, Stulberg SD, Adams AD, Harden RN, Bruehl S, Stanos SP, Houle T. Predicting total knee replacement pain: a prospective, observational study. Clin Orthop Relat Res. 2003;416:27-36.

10. Butler RA, Rosenzweig S, Myers L, Barrack RL. The Frank Stinchfield Award. The impact of socioeconomic factors on outcome after THA: a prospective, randomized study. Clin Orthop Relat Res. 2011;469:339-347.

11. Cai X, Cram P, Vaughan-Sarrazin M. Are African American patients more likely to receive a total knee arthroplasty in a lowquality hospital? Clin Orthop Relat Res. 2012;470:1185-1193.

12. Centers for Disease Control and Prevention. Prevalence of cholesterol screening and high blood cholesterol among adults United States, 2005, 2007, and 2009. MMWR Morb Mortal Wkly Rep. 2012;61:697-702.

13. Centers for Medicare \& Medicaid Services. Medicare Contractor Provider Satisfaction Survey (MCPSS) Public Report 2011. Final Report July 29, 2011, Revised December 2011. Available at: http://www.cms.gov/Research-Statistics-Data-and-Systems/Rese arch/MCPSS/Downloads/MCPSS_Public_Report.pdf. Accessed October 3, 2012.

14. Chandran N, Amirouche F, Gonzalez MH, Hilton KM, Barmada $\mathrm{R}$, Goldstein W. Optimisation of the posterior stabilised tibial post for greater femoral rollback after total knee arthroplasty-a finite element analysis. Int Orthop. 2009;33:687-693.

15. Chatman AB, Hyams SP, Neel JM, Binkley JM, Stratford PW, Schomberg A, Stabler M. The Patient-Specific Functional Scale: measurement properties in patients with knee dysfunction. Phys Ther. 1997;77:820-829.

16. Dennis DA, Komistek RD. Kinematics of mobile-bearing total knee arthroplasty. Instr Course Lect. 2005;54:207-220.

17. Dunlop DD, Manheim LM, Song J, Sohn MW, Feinglass JM, Chang HJ, Chang RW. Age and racial/ethnic disparities in arthritis-related hip and knee surgeries. Med Care. 2008;46:200208.

18. Endres S. High-flexion versus conventional total knee arthroplasty: a 5-year study. J Orthop Surg (Hong Kong). 2011;19:226-229.

19. Epstein AJ, Gray BH, Schlesinger M. Racial and ethnic differences in the use of high-volume hospitals and surgeons. Arch Surg. 2010;145:179-186. 
20. Fisher DA, Dierckman B, Watts MR, Davis K. Looks good but feels bad: factors that contribute to poor results after total knee arthroplasty. J Arthroplasty. 2007;22:39-42.

21. Franklin PD, Li W, Ayers DC. The Chitranjan Ranawat Award. Functional outcome after total knee replacement varies with patient attributes. Clin Orthop Relat Res. 2008;466:2597-2604.

22. Freburger JK, Holmes GM, Ku LJ, Cutchin MP, Heatwole-Shank $\mathrm{K}$, Edwards LJ. Disparities in post-acute rehabilitation care for joint replacement. Arthritis Care Res (Hoboken). 2011;63:1020-1030.

23. Goyal N, McKenzie J, Sharkey PF, Parvizi J, Hozack WJ, Austin MS. The 2012 Chitranjan Ranawat Award. Intraarticular analgesia after TKA reduces pain: a randomized, double-blinded, placebo-controlled, prospective study. Clin Orthop Relat Res. 2013;471:64-75.

24. Hanchate AD, Zhang Y, Felson DT, Ash AS. Exploring the determinants of racial and ethnic disparities in total knee arthroplasty: health insurance, income, and assets. Med Care. 2008;46:481-488.

25. Horn KK, Jennings S, Richardson G, Vliet DV, Hefford C, Abbott JH. The Patient-Specific Functional Scale: psychometrics, clinimetrics, and application as a clinical outcome measure. $J$ Orthop Sports Phys Ther. 2012;42:30-42.

26. Ibrahim SA, Stone RA, Han X, Cohen P, Fine MJ, Henderson WG, Khuri SF, Kwoh CK. Racial/ethnic differences in surgical outcomes in veterans following knee or hip arthroplasty. Arthritis Rheum. 2005;52:3143-3151.

27. Irgit K, Nelson CL. Defining racial and ethnic disparities in THA and TKA. Clin Orthop Relat Res. 2011;469:1817-1823.

28. Jacobs W, Anderson P, Limbeek J, Wymenga A. Mobile bearing vs fixed bearing prostheses for total knee arthroplasty for post-operative functional status in patients with osteoarthritis and rheumatoid arthritis. Cochrane Database Syst Rev. 2004;2:CD003130.

29. Jacobs WC, Clement DJ, Wymenga AB. Retention versus sacrifice of the posterior cruciate ligament in total knee replacement for treatment of osteoarthritis and rheumatoid arthritis. Cochrane Database Syst Rev. 2005;4:CD004803.

30. Jolles BM, Grzesiak A, Eudier A, Dejnabadi H, Voracek C, Pichonnaz C, Aminian K, Martin E. A randomised controlled clinical trial and gait analysis of fixed- and mobile-bearing total knee replacements with a five-year follow-up. J Bone Joint Surg Br. 2012;94:648-655.

31. Kim YH, Kim JS, Choe JW, Kim HJ. Long-term comparison of fixed-bearing and mobile-bearing total knee replacements in patients younger than fifty-one years of age with osteoarthritis. $J$ Bone Joint Surg Am. 2012;94:866-873.

32. Kim YH, Kook HK, Kim JS. Comparison of fixed-bearing and mobile-bearing total knee arthroplasties. Clin Orthop Relat Res. 2001;392:101-115.

33. Kolisek FR, Mont MA, Costa CR, Johnson AJ, Jaggard CE. A comparison study of two cruciate-retaining total knee designs: a preliminary report. Surg Technol Int. 2011;XXI:194-198.

34. Kurtz S, Ong K, Lau E, Mowat F, Halpern M. Projections of primary and revision hip and knee arthroplasty in the United States from 2005 to 2030. J Bone Joint Surg Am. 2007;89:780785 .

35. Kurtz SM, Lau E, Ong K, Zhao K, Kelly M, Bozic KJ. Future young patient demand for primary and revision joint replacement: national projections from 2010 to 2030. Clin Orthop Relat Res. 2009;467:2606-2612.

36. Lavernia CJ, Alcerro JC, Brooks LG, Rossi MD. Mental health and outcomes in primary total joint arthroplasty. $J$ Arthroplasty. 2012;27:1276-1282.

37. Lavernia CJ, Alcerro JC, Contreras JS, Rossi MD. Ethnic and racial factors influencing well-being, perceived pain, and physical function after primary total joint arthroplasty. Clin Orthop Relat Res. 2011;469:1838-1845.
38. Lieberman JR, Dorey F, Shekelle P, Schumacher L, Thomas BJ, Kilgus DJ, Finerman GA. Differences between patients' and physicians' evaluations of outcome after total hip arthroplasty. J Bone Joint Surg Am. 1996;78:835-838.

39. Likert R. A technique for the measurement of attitudes. Arch Psychol. 1932;22:1-55.

40. Long WJ, Scuderi GR. High-flexion total knee arthroplasty. J Arthroplasty. 2008;23:6-10.

41. Lozano-Calderon SA, Shen J, Doumato DF, Greene DA, Zelicof SB. Cruciate-retaining vs posterior-substituting inserts in total knee arthroplasty: functional outcome comparison. J Arthroplasty. 2013;28:234-242.el.

42. MacDonald SJ, Charron KD, Bourne RB, Naudie DD, McCalden $\mathrm{RW}$, Rorabeck $\mathrm{CH}$. The John Insall Award. Gender-specific total knee replacement: prospectively collected clinical outcomes. Clin Orthop Relat Res. 2008;466:2612-2616.

43. Maloney WJ. National Joint Replacement Registries: has the time come? J Bone Joint Surg Am. 2001;83:1582-1585.

44. Meftah M, Wong AC, Nawabi DH, Yun RJ, Ranawat AS, Ranawat CS. Pain management after total knee arthroplasty using a multimodal approach. Orthopedics. 2012;35:e660-e664.

45. Mont MA, Mayerson JA, Krackow KA, Hungerford DS. Total knee arthroplasty in patients receiving Workers' Compensation. J Bone Joint Surg Am. 1998;80:1285-1290.

46. Noble PC, Conditt MA, Cook KF, Mathis KB. The John Insall Award. Patient expectations affect satisfaction with total knee arthroplasty. Clin Orthop Relat Res. 2006;452:35-43.

47. Nunley RM, Ruh EL, Zhang Q, Della Valle CJ, Engh CA Jr, Berend ME, Parvizi J, Clohisy JC, Barrack RL. Do patients return to work after hip arthroplasty surgery? J Arthroplasty. 2011;26(6 suppl):92-98.e1-3.

48. Nwachukwu BU, Kenny AD, Losina E, Chibnik LB, Katz JN. Complications for racial and ethnic minority groups after total hip and knee replacement: a review of the literature. J Bone Joint Surg Am. 2010;92:338-345.

49. Pagnano MW, Trousdale RT, Stuart MJ, Hanssen AD, Jacofsky DJ. Rotating platform knees did not improve patellar tracking: a prospective, randomized study of 240 primary total knee arthroplasties. Clin Orthop Relat Res. 2004;428:221-227.

50. Price AJ, Longino D, Rees J, Rout R, Pandit H, Javaid K, Arden N, Cooper C, Carr AJ, Dodd CA, Murray DW, Beard DJ. Are pain and function better measures of outcome than revision rates after TKR in the younger patient? Knee. 2010;17:196-199.

51. Radler BT, Ryff CD. Who participates? Accounting for longitudinal retention in the MIDUS national study of health and wellbeing. J Aging Health. 2010;22:307-331.

52. Rahman MM, Kopec JA, Sayre EC, Greidanus NV, Aghajanian J, Anis AH, Cibere J, Jordan JM, Badley EM. Effect of sociodemographic factors on surgical consultations and hip or knee replacements among patients with osteoarthritis in British Columbia, Canada. J Rheumatol. 2011;38:503-509.

53. Riddle DL, Wade JB, Jiranek WA, Kong X. Preoperative pain catastrophizing predicts pain outcome after knee arthroplasty. Clin Orthop Relat Res. 2010;468:798-806.

54. Santaguida PL, Hawker GA, Hudak PL, Glazier R, Mahomed NN, Kreder HJ, Coyte PC, Wright JG. Patient characteristics affecting the prognosis of total hip and knee joint arthroplasty: a systematic review. Can J Surg. 2008;51:428-436.

55. Scuderi GR, Hedden DR, Maltry JA, Traina SM, Sheinkop MB, Hartzband MA. Early clinical results of a high-flexion, posteriorstabilized, mobile-bearing total knee arthroplasty: a US investigational device exemption trial. J Arthroplasty. 2012;27:421-429.

56. Singh JA, O'Byrne M, Harmsen S, Lewallen D. Predictors of moderate-severe functional limitation after primary total knee arthroplasty (TKA): 4701 TKAs at 2-years and 2935 TKAs at 5-years. Osteoarthritis Cartilage. 2010;18:515-521. 
57. Singh JA, O’Byrne MM, Colligan RC, Lewallen DG. Pessimistic explanatory style: a psychological risk factor for poor pain and functional outcomes two years after knee replacement. $J$ Bone Joint Surg Br. 2010;92:799-806.

58. Skinner J, Zhou W, Weinstein J. The influence of income and race on total knee arthroplasty in the United States. $J$ Bone Joint Surg Am. 2006;88:2159-2166.

59. Song EK, Jung WB, Yoon TR, Park KS, Seo HY, Seon JK. Comparison of outcomes after bilateral simultaneous total knee arthroplasty using gender-specific and unisex knees. J Arthroplasty. 2012;27:226-231.

60. Stratford P, Gill C, Westaway M, Binkley J. Assessing disability and change on individual patients: a report of a patient specific measure. Physiother Can. 1995;47:258-263.
61. Thomsen MG, Husted H, Bencke J, Curtis D, Holm G, Troelsen A. Do we need a gender-specific total knee replacement? A randomised controlled trial comparing a high-flex and a genderspecific posterior design. J Bone Joint Surg Br. 2012;94:787-792.

62. Ulrich SD, Mont MA, Bonutti PM, Seyler TM, Marker DR, Jones LC. Scientific evidence supporting computer-assisted surgery and minimally invasive surgery for total knee arthroplasty. Expert Rev Med Devices. 2007;4:497-505.

63. Wainwright C, Theis JC, Garneti N, Melloh M. Age at hip or knee joint replacement surgery predicts likelihood of revision surgery. J Bone Joint Surg Br. 2011;93:1411-1415.

64. Walker PS, Heller Y, Cleary DJ, Yildirim G. Preclinical evaluation method for total knees designed to restore normal knee mechanics. J Arthroplasty. 2011;26:152-160. 